\title{
Metastasis of adrenocortical carcinoma to the heart
}

\author{
Monika Skrzypiec-Spring1, Justyna Kuliczkowska-Płaksej², Barbara Stachowska², Adam Szeląg1, \\ Wojciech Kustrzycki ${ }^{3}$, Marek Bolanowski ${ }^{2}$
}

${ }^{1}$ Department of Pharmacology, Wroclaw Medical University, Wroclaw, Poland

${ }^{2}$ Department of Endocrinology, Diabetes and Isotope Therapy, Wroclaw Medical University, Wroclaw, Poland

${ }^{3}$ Department of Clinical Nursing, Wroclaw Medical University, Wroclaw, Poland

Key words: adrenocortical carcinoma; metastasis; heart

A 32-year-old woman was referred to the Department of Endocrinology, Diabetes and Isotope Therapy from a Gynaecology and Obstetrics Department to which she presented on the $4^{\text {th }}$ day of childbed with severe headache, hypertension, bilateral leg oedema, and lumbar pain. Chest radiograph showed moderate amounts of right pleural effusion and compression atelectasis. Abdominal sonography revealed a heterogeneous hypoechogenic mass in the area of the upper pole of the right kidney. This finding was confirmed by computed tomography, which showed a 6.2/7.4/6.0 cm sized mass arising from right adrenal gland with inferior vena cava extension to the level of the right atrium.

On admission the patient demonstrated elevated blood pressure, headache, bilateral leg oedema, and severe abdominal and lumbar pain. No signs of hypercortisolaemia or hyperandrogenism were observed on physical examination.

Laboratory results are presented in Table 1.

Laboratory findings revealed leukocytosis, elevated levels of C-reactive protein, alanine aminotransferase, fibrinogen and D-dimer, and thrombocytopaenia. Urine test showed proteinuria and erythrocyturia in urine sediment. Hormonal study revealed an increased serum concentration of cortisol measured in the morning and at midnight, as well as decreased plasma renin activity during recumbency and after 120 minutes of upright posture. Supine aldosterone and aldosterone after 120 minutes of upright posture were elevated. Serum testosterone and DHEA-S levels were very high.

On the basis of the imaging and laboratory findings, the diagnosis of hormonally active adrenocortical carcinoma (ACC) was established.

Because of extension of the tumour to the level of the right atrium via the inferior vena cava, trans-thoracic echocardiography (TTE) was performed. In TTE a large
Table 1. Laboratory results of the patient

\begin{tabular}{|c|c|c|}
\hline & Results & $\begin{array}{l}\text { Reference } \\
\text { range }\end{array}$ \\
\hline Leukocytes $[\mathrm{K} / \mu \mathrm{L}]$ & 11.7 & $4-10$ \\
\hline Platelets $[\mathrm{K} / \mu \mathrm{L}]$ & 91 & $130-400$ \\
\hline C-reactive protein [mg/l] & 38.6 & $0-3$ \\
\hline Alanine aminotransferase [U/I] & 78 & $5-37$ \\
\hline Fibrinogen [mg\%] & 800 & $200-450$ \\
\hline D-dimer [ng/mL] & 6950 & $70-490$ \\
\hline Cortisol at 6 a.m. [ng/mL] & 255.3 & $94-260$ \\
\hline Cortisol at 8 a.m. [ng/mL] & 316.3 & $94-260$ \\
\hline Cortisol at 8 p.m. [ng/mL] & 312.2 & $18-127$ \\
\hline Cortisol at 12 p.m. [ng/mL] & 355.9 & $18-127$ \\
\hline $\begin{array}{l}\text { Plasma renin activity [during } \\
\text { recumbency] [ng/mL/h] }\end{array}$ & 0.15 & $0.51-2.64$ \\
\hline $\begin{array}{l}\text { Plasma renin activity [after } 120 \text { minutes } \\
\text { of upright posture] }[\mathrm{ng} / \mathrm{mL} / \mathrm{h}]\end{array}$ & 0.39 & $0.98-4.18$ \\
\hline Supine aldosterone $[\mathrm{pg} / \mathrm{mL}]$ & 21.3 & 29.4-161.5 \\
\hline $\begin{array}{l}\text { Aldosterone [after } 120 \text { minutes of } \\
\text { upright posture] [pg/mL] }\end{array}$ & 30.6 & $38.1-313.3$ \\
\hline $\begin{array}{l}\text { Metoxycatecholamines in } 24 \mathrm{~h} \text { urine } \\
{[\mu \mathrm{g} / 24 \mathrm{~h}]}\end{array}$ & 170 & $100-1000$ \\
\hline Prolactin [ng/mL] & 15.9 & $1.9-25$ \\
\hline $\mathrm{FSH}[\mathrm{mlU} / \mathrm{mL}]$ & $<0.1$ & $2.8-11.3$ \\
\hline LH [mlU/mL] & 0.12 & $1.1-11.6$ \\
\hline Testosterone [ng/mL] & 6.16 & $0.65-1.19$ \\
\hline DHEA-S $[\mu \mathrm{g} / \mathrm{dl}]$ & $>1000$ & $35-430$ \\
\hline Estradiol [pg/mL] & 45.2 & $20-160$ \\
\hline ACTH $[\mathrm{pg} / \mathrm{mL}]$ & 5.2 & $0-46$ \\
\hline $\mathrm{TSH}[\mu \mathrm{IU} / \mathrm{mL}]$ & 0.33 & $0.4-4$ \\
\hline fT4 [pmol/l] & 16.73 & 9-20 \\
\hline fT3 [pmol/l] & 2.62 & $4-8.3$ \\
\hline
\end{tabular}

$\mathrm{FSH}$ - follicle stimulating hormone; $\mathrm{LH}$ — luteinizing hormone;

DHEA-S — dehydroepiandrosterone sulphate; ACTH — adrenocorticotropic hormone; TSH — thyroid stimulating hormone; $\mathrm{TT} 4$ — free thyroxine;

fT3 - free triiodothyronine 


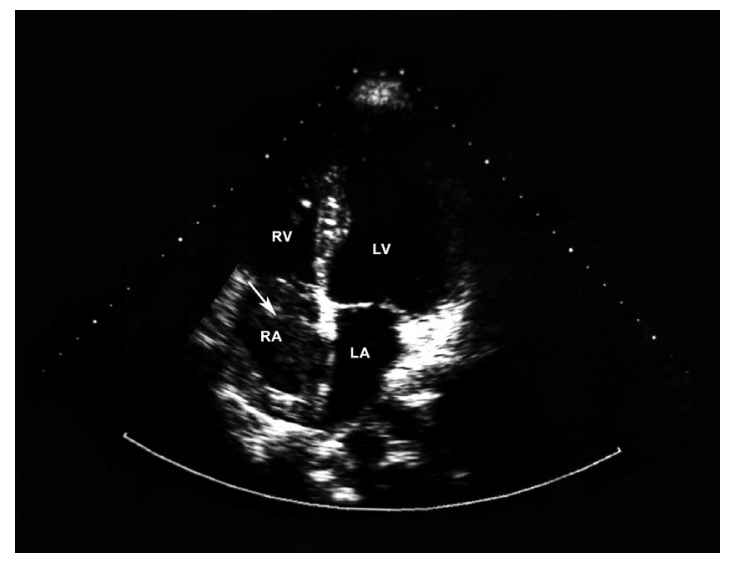

Figure 1. Trans-thoracic echocardiography (TTE) at the time of initial diagnosis - apical 4-chamber view. Arrow indicates a large right atrial mass that occupies nearly the entire space of the right atrium. $L A$ - left atrium; $L V$ - left ventricle; $R A$ - right atrium; $R V$ - right ventricle

mass $(3.8 / 2.8 \mathrm{~cm})$ attached to the atrial roof and the upper part of the interatrial septum was identified within the right atrium. In addition, a mobile mass, measuring $1.6 / 2.2 \mathrm{~cm}$, attached to the atrial side of the anterior leaflet of the tricuspid valve, was detected. An echolucent area within the mobile mass periodically communicating with the right ventricle was observed (Fig. 1). A structure and function of the left ventricle were normal. Doppler study revealed mild tricuspid and mitral regurgitation and mild pulmonary hypertension.

Due to the risk of embolization, the patient underwent urgent cardiosurgery, and a large intra-atrial mass and tumour thrombi in the inferior vena cava were removed (Fig. 2). Pathologic examination confirmed the diagnosis of ACC documenting ACC cells and a large area of necrosis within the tumour.

Post-operatively, the patient did well and on the $19^{\text {th }}$ day was referred to the urological ward for further treatment.

ACC is a rare malignant neoplasm with high metastatic potential. It usually metastasizes to the lung, liver, kidney, renal veins, lymph nodes, and the inferior vena cava. Cardiac involvement of the tumour is very rare, and few cases have been reported [1-5]. Most of the described cases of cardiac involvement of ACC showed direct invasion of the inferior vena cava and right atrium. Infiltration of the inter-atrial septum by metastatic tumour or clusters of tumour cells on heart valves are very rare [5]. Most of the cases, including the present case, originate from the right adrenal gland, which may be explained by the direct course of the right adrenal vein to the inferior vena cava.

The tumour-node-metastasis (TNM) classification for ACC defines stage I and II as strictly localized

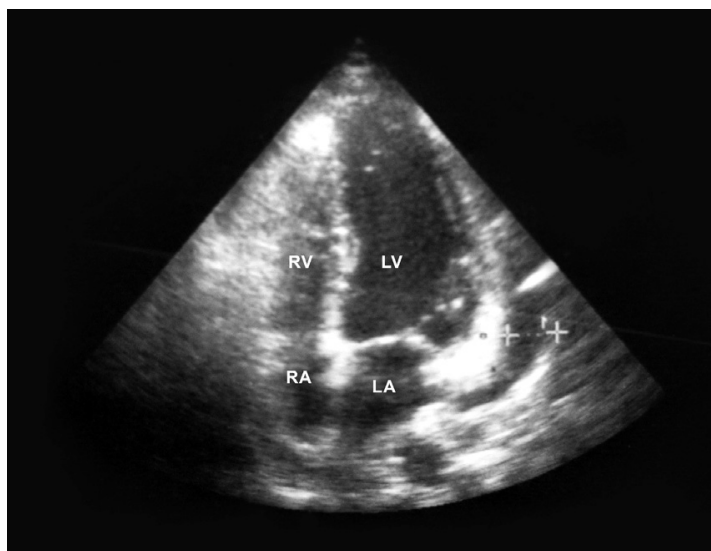

Figure 2. Follow-up, postoperative trans-thoracic echocardiography (TTE) - apical 4-chamber view. Normal right atrium. LA - left atrium; $L V$ - left ventricle; $R A$ - right atrium; $R V$ - right ventricle

tumours. Tumours infiltrating surrounding tissue, regional lymph nodes, or with extension to the vena cava and/or renal vein are classified as stage III. Stage IV is characterized by the presence of distant metastases. According to the tumour-node-metastasis (TNM) classification for ACC, our patient had advanced (stage IV) ACC with vena cava and right atrium invasion. Currently, complete tumour resection is the therapeutic approach to localized ACCs (stages I, II, and some III). Adjuvant chemotherapy and tumoural bed irradiation can be associated after surgery. In metastatic ACCs surgery is of benefit only in a limited number of patients. For patients with tumour extension to the vena cava and right atrium the treatment of choice is complete surgical resection of both the primary tumour and the cavoatrial mass. In the case of our patient, because of the high risk of pulmonary artery embolism associated with balloting mass, we decided to carry out urgent cardiosurgery, and removal of primary tumour was postponed.

\section{References}

1. Goldberg AD, Blankstein R, Padera RF. Tumors metastatic to the heart. Circulation. 2013; 128(16): 1790-1794, doi: 10.1161/CIRCULATIONAHA.112.000790, indexed in Pubmed: 24126323.

2. Iezzi F, Quarti A, Surace C, et al. Paediatric Nonfunctioning Adrenocortical Carcinoma with Extension up to Right-Side Heart: Cardiac Surgery Approach. Case Rep Cardiol. 2016; 2016: 2321017, doi: 10.1155/2016/2321017, indexed in Pubmed: 27493811.

3. Kim KH, Park JC, Lim SY, et al. A case of non-functioning huge adrenocortical carcinoma extending into inferior vena cava and right atrium. J Korean Med Sci. 2006; 21(3): 572-576, doi: 10.3346/jkms.2006.21.3.572, indexed in Pubmed: 16778409

4. Chesson JP, Theodorescu D. Adrenal tumor with caval extension--case report and review of the literature. Scand J Urol Nephrol. 2002; 36(1): 71-73, doi: 10.1080/003655902317259409, indexed in Pubmed: 12002362.

5. Luton JP, Cerdas S, Billaud L, et al. Clinical features of adrenocortical carcinoma, prognostic factors, and the effect of mitotane therapy. N Engl J Med. 1990; 322(17): 1195-1201, doi: 10.1056/NEJM199004263221705, indexed in Pubmed: 2325710. 